\title{
Sleep Duration Determines Excess Body Mass Index among Young Adults in Surabaya
}

\author{
Niwanda Yogiswara ${ }^{1} \mathbb{D}$, Widati Fatmaningrum ${ }^{2^{*}} \mathbb{D}$, Lilik Herawati ${ }^{3}$
}

${ }^{1}$ Faculty of Medicine, Universitas Airlangga, Surabaya, Indonesia.

2Department of Public Health and Preventive Medicine, Faculty of Medicine, Universitas Airlangga, Surabaya, Indonesia. ${ }^{3}$ Department of Physiology and Biochemistry, Universitas Airlangga, Surabaya, Indonesia.

\section{A B S T R A C T}

Introduction: Lack of sleep duration is one of the risk factors that cause excess body mass index (BMI). One of the mechanisms are by regulating an increase in appetite and reducing the energy used. This study aimed to identify the relationship between sleep duration and excess BMI in young adults.

Methods: This descriptive-analytic observational study with cross-sectional design was conducted on 70 respondents aged 18-25 years old. The primary outcomes measured were sleep duration and BMI. Sleep duration was grouped as $<7$ hours (short sleepers), and $\geq 7$ hours. BMI was classified as $18.5-22.9$ as normal, and $\geq 23$ as excess BMI (including overweight and obesity) according to Asia-Pacific classification. Data were analyzed using SPSS 21 software.

Results: The study showed that the prevalence of excess BMI was higher in respondents with sleep deprivation ( $<7$ hours) of $67 \%$ compared to respondents with enough sleep of $33 \%$. The average sleep duration was 42 minutes shorter on respondents with excess BMI with an average of 6.1 hours and 6.8 hours on normalweight respondents. According to the results of the study, there was a significant relationship between sleep duration and excess BMI $(p<0.05)$.

Conclusion: The study revealed that sleep duration was related with excess BMI in young adults.

\footnotetext{
* Correspondence: widatifatmaningrum@yahoo.com

JUXTA: Jurnal IImiah Mahasiswa Kedokteran Universitas Airlangga p-ISSN: 1907-3623; e-ISSN: 2684-9453

DOI: 10.20473/juxta.V13I12022.18-21

Open access under Creative Commons Attribution-ShareAlike 4.0 International License (CC-BY-SA)
}

ARTICLEINFO

Article history:

Received 14 March 2021

Received in revised form 5 November 2021

Accepted 27 December 2021

Available online 5 January 2022

\section{Keywords:}

BMI,

Obesity,

Sleep duration,

Surabaya,

Young adult. 


\section{Introduction}

The prevalence of short sleepers has increased steadily in the last few decades. Whereas the prevalence of very short sleepers ( $<5$ hours) and short sleepers (56 hours) has increased 10 -fold. Sleep has an essential role in the daily life of all ages, including adults and the growth of children and adolescents. ${ }^{1,2}$

Several studies have demonstrated that short sleep duration is linked with adverse health outcomes, including morbidity and mortality, and associated with cardiovascular disease, type 2 diabetes mellitus, and obesity. ${ }^{3}$ Obesity and overweight contributed as a major risk factor for noncommunicable diseases and even some malignancies that reduce the overall quality of life. ${ }^{4}$ With the increasing prevalence of obesity in Indonesian adults, starting from 2007 at $10.5 \%$ and in 2013 increased to $14.8 \%$, the factor promoting it should be investigated, including sleep. ${ }^{5}$

Several mechanisms have been put to describe this sleep and obesity association, including added awake hours which give more opportunity to eat, increased hunger from hormones signaling appetite and reduced satiety from hormones promoting satiation, altered thermoregulation, and increased fatigue which results in lower physical activity. ${ }^{6}$

Lack of sleep causes weight gain by regulating an increase in how much food is eaten and reducing the energy used. ${ }^{7}$ A study in America also showed that people who sleep less have lower levels of Leptin and higher levels of Ghrelin than normal people. A reduction in the average night's sleep from 8 to 5 hours caused a decrease of $15.5 \%$ Leptin and an increase of $14.9 \%$ Ghrelin. ${ }^{8}$ Leptin is a hormone produced by adipose cells, this cell regulates energy balance by inhibiting hunger. Leptin functions are contrary to the Ghrelin, a hormone produced by the digestive tract to create hunger. Both of these hormones act on receptors in the hypothalamic arcuate nucleus to regulate appetite. ${ }^{9}$ The combination of low Leptin and high Ghrelin tends to increase appetite and potentially increases body weight. People who did not get enough sleep were also more tired during the day, and as a result, it may reduce their physical activity. ${ }^{10}$

The previous study conducted by Capers PL (2015) showed that sleep deprivation would lead to positive energy balance, in which the energy intake is increased by at least $300 \mathrm{kcal} / \mathrm{d}$ and if sleep deprivation persists over time, it will eventually cause weight gain. ${ }^{11}$ Sleep deprivation often occurs in young adult groups of 18-25 years old, it occurs in all group of adults including the ones who have insomnia and without insomnia. ${ }^{12}$ Cross-cultural studies in lowincome and middle-income countries in various regions of the world are still lacking, and are very important to identify the relationship between sleep patterns and obesity. ${ }^{13}$ The link between sleep and obesity was critical in young adults, including university students, due to accompanying lifestyle changes such as sleep patterns, dietary, and physical activity behavior which was attributable in the transition from school to the university. ${ }^{14}$
Previous study in Indonesia conducted by Marfuah (2013) showed that there was a relationship between sleep duration and obesity in children. However, the study was limited to age 6-12 years old. ${ }^{15}$ Therefore, it is worth conducting a new study including the young adults age group.

\section{Methods}

This was a descriptive-analytic observational study with a cross-sectional design. The study conducted between July 2016 until January 2017 at Faculty of Medicine, Universitas Airlangga, Surabaya. Data sources were obtained from interviews in the form of a questionnaire about sleep duration and measurements of body mass index (BMI). The study population was class of 2013 students of Faculty of Medicine, Universitas Airlangga, Surabaya. The sample size was determined based on the formula of the cross-sectional study sample of 70 people. The research sample was taken using purposive sampling. The inclusion criteria included being 18-25 years old, healthy, and signed the informed consent form. Respondents were excluded if they were reported to use a drug with hypnotic effects, daily caffeine usage, and were in weight-reducing or gaining programs. All respondents filled in questionnaires that included questions regarding their sleep duration, physical activity, daytime nap, and tobacco use. The study was approved by the Ethics Committee of Faculty of Medicine, Universitas Airlangga. All participants gave their informed consent before participating.

The dependent variable included in this study was BMI, while the independent variables were gender, smoking status, physical activity, and sleep duration. All variables were obtained using primary data sources. BMI variables were obtained from the results of BMl formula which was weight in kilograms divided by height in meters squared. The weight was measured using a digital weight scale and the height was measured with stature meter. BMI classification used in this study was the AsiaPacific classification; a person is categorized as excess $\mathrm{BMI}$ if they have a BMI score of $\geq 23$, which includes overweight and obesity classification. ${ }^{16}$

The smoking variable was categorized as smoking and non-smoking. Physical activity variables were categorized as mild, moderate, and high intensity. Sleep duration was categorized as normal sleepers ( $\geq 7$ hours) and short sleepers ( $<7$ hours) based on sleep recommendations for young adults age group according to the National Sleep Foundation. ${ }^{17}$ Variable data were served descriptively as mean, median, mode, and standard deviation, and presented in the frequency distribution. Statistical analysis was performed with SPSS software, version 21. Bivariate analyses were conducted using the $x 2$ with a $p$-value of $<0.05$ which was considered to be statistically significant. 


\section{Results}

From a total of 70 respondents who met the inclusion criteria, their age ranged from 19-22 years old, with the majority of men with a percentage of $67 \%$ while women were only $33 \%$. Most of the respondents did mild intensity physical activity with a percentage of $57 \%$. After identifying each subject based on their duration of sleep, the intensity of physical activity was dominated by the mild intensity with a percentage of $60 \%$ in short sleepers and $53 \%$ in normal sleepers. Whereas for each duration of sleep, there were smokers with a total amount of $13 \%$. Compared to the normal sleepers, respondents with sleep deprivation $(<7$ hours) had a higher prevalence in excess BMI (67\% vs $33 \%)$.

Table 1. Characteristics of the respondents according to sleep duration

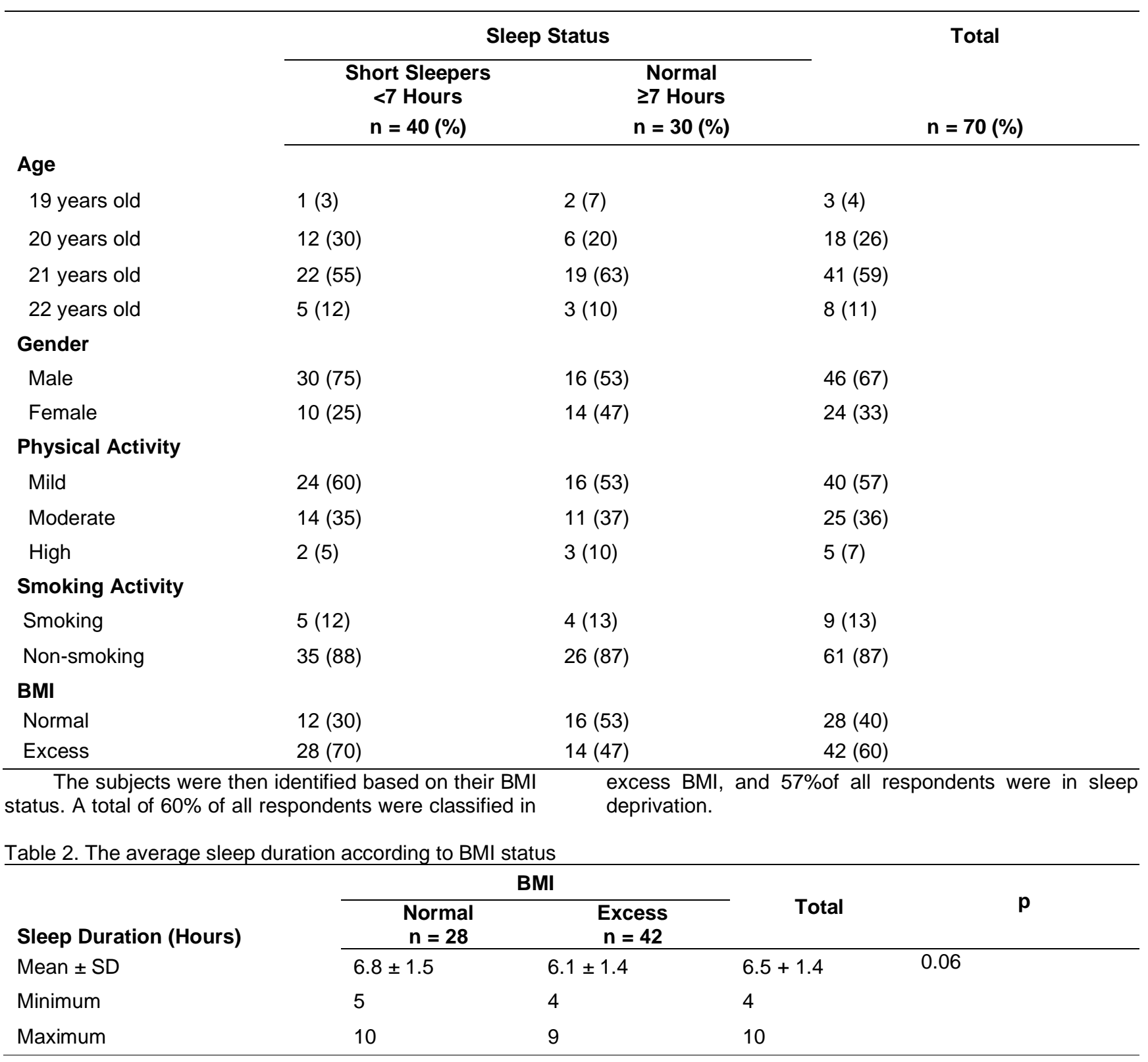

The average sleep duration of all respondents was 6.5 hours. Table 2 also showed that respondents with excess BMI had a difference in sleep duration compared to respondents with normal BMI, which was 42 minutes shorter, with an average sleep duration of 6.1 hours and
6.8 hours respectively. However, the analysis showed that the diffference of the average sleep duration between the normal and excess BMI were not significant $(p=0.06)$.

Table 3. Bivariate analysis across variable according to BMI status

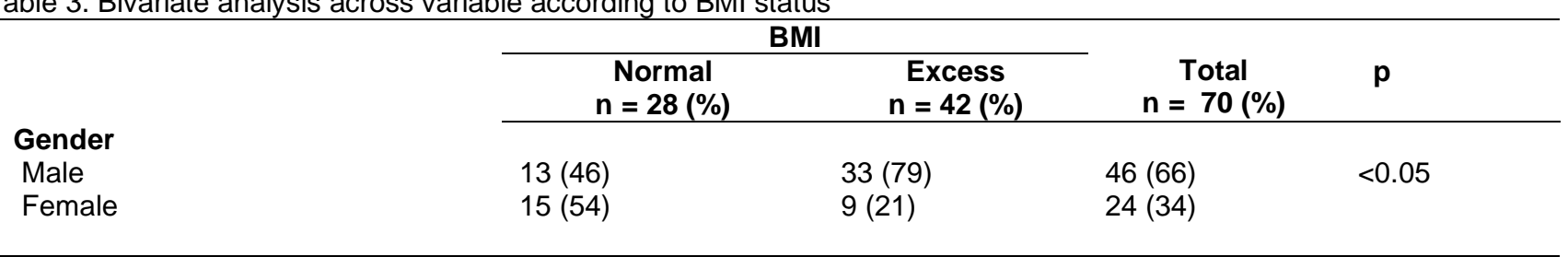




\begin{tabular}{|c|c|c|c|c|}
\hline \multicolumn{5}{|l|}{ Physical Activity } \\
\hline Mild & $13(46)$ & $27(65)$ & $40(5)$ & \multirow[t]{3}{*}{0.12} \\
\hline Moderate & $11(39)$ & 14 (33) & $25(36)$ & \\
\hline High & $4(15)$ & $1(2)$ & $5(7)$ & \\
\hline \multicolumn{5}{|l|}{ Smoking } \\
\hline Yes & $4(14)$ & $5(12)$ & $9(13)$ & \multirow[t]{2}{*}{0.52} \\
\hline No & $24(86)$ & 37 (88) & $61(87)$ & \\
\hline \multicolumn{5}{|l|}{ Sleep Status } \\
\hline Short Sleeper (<7 Hours) & $12(43)$ & $28(67)$ & $40(57)$ & \multirow[t]{2}{*}{$<0.05$} \\
\hline Normal ( $\geq 7$ hours) & $16(57)$ & $14(33)$ & $30(43)$ & \\
\hline
\end{tabular}

According to the respondents' BMI status, study analysis using chi-square obtained a significant $(p<0.05)$ in gender and sleep duration. It explains that there was a significant relationship between gender and sleep duration with excess BMI. However, no significant relationship was found in physical activity and smoking $(p=0.12 \& 0.52$; respectively).

\section{Discussion}

The study showed that the prevalence of excess BMI was higher in respondents with sleep deprivation $(<7$ hours) $(67 \%)$ compared to respondents with enough sleep (33\%). It was consistent with previous studies in children aged 5-10 years old in Australia conducted by Shi, et al., (2010) which stated children who sleep less than 9 hours have almost double prevalence of obesity compared to those who sleep for 10 hours, which was $22.3 \%$ compared to $11,5 \% .{ }^{16}$

All respondents had a mean of sleep duration of 6.5 hours, which was categorized as short sleepers based on the National Sleep Foundation recommendation (2017). ${ }^{17}$ This result may explain the previous study that stated lifestyle changes such as sleep patterns was attributable in the young adult transition from school to the university. ${ }^{14}$

Table 2 also showed that respondents with excess BMI had a difference in sleep duration compared to respondents with normal BMI, which was 42 minutes shorter, with an average sleep duration of 6.1 hours and 6.8 hours respectively. This result was consistent with the previous study which showed that the average sleep duration of the obese respondent was 16 minutes shorter compared to non-obese. ${ }^{15}$

The majority of respondents were men at $67 \%$ while women were only $33 \%$. The study analysis found that there was a relationship between gender and excess BMI $(p<$ 0.05 ). The prevalence of overweight and obesity among men and women varies greatly within and between countries. Overweight and obesity are more likely to occur among women in the Middle East and North Africa. While in developed countries, more men are overweight than women. The variation of sociocultural and enviromental factor throughout the world may attributable to the increase of gender disparities in excess weight gain. ${ }^{18}$

Bodyweight gain could be caused by changes in a person's level of activity. From Table 1 it can be seen that the overall major intensity of physical activity was mild which was equal to $57 \%$. In each group's duration of sleep, the intensity of activity was also dominated by the mild intensity with a percentage of $60 \%$ in normal sleepers and $53 \%$ in short sleepers ( $<7$ hours). These results are in accordance with data from the National Sleep Foundation (2012), which stated the lack of sleep duration will have an impact on lack of activity and is followed by an increase in calorie intake, which is one of the causes of obesity problems. A study conducted by Patel \& Hu (2008) also showed that sleep deprivation for a long period causes fatigue and ultimately leads to decreased physical activity. People who sleep less tend to spend more time watching TV and have less physically active time than people who get enough sleep. ${ }^{19}$

This study analysis showed that there was no relationship found between physical activity and excess $\mathrm{BMI}$, as explained in the previous study by Patel \& $\mathrm{Hu}$ (2008), that the differences in physical activity or watching TV are not directly adequate to explain the relationship between lack of sleep and weight gain. ${ }^{19}$

According to the study analysis, smoking was not related with excess BMI. It is in contrary with a crosssectional study conducted by Dare (2015) that showed there was a significant difference between smoking and $\mathrm{BMI}$, whereas active smokers were less likely to be obese than non-smokers. ${ }^{20}$ Nevertheless, the subgroup analysis of the study showed that the difference was not significant in younger participants and those living in areas of residence. The previous study by Zbikowski (2012) showed that the link between smoking and obesity is not completely understood, and published studies have produced conflicting results. Meanwhile, some studies have shown no significant association between smoking status and BMI. $^{21}$

The result of the analysis between sleep duration and excess BMl obtained $p<0.05$. It can be concluded that there was a significant relationship between sleep duration with excess BMI. The result of this study was consistent with the previous study conducted by Marfuah (2013) that showed a significant relationship between sleep duration and obesity in children. ${ }^{15}$

Several mechanisms have been put to describe the link between the association of sleep and obesity. Lack of sleep duration would provide more awake hours and provides more opportunity to eat. The change of hormones regulating appetite and hormones regulating satiation would lead to increased hunger. Short sleepers were also more likely to be fatigue, which could lead to lower activity levels. ${ }^{6}$ This study speculated that sleep deprivation leads to weight gain, either by increasing the amount of food eaten or reducing the energy burned. ${ }^{19}$ The first 
mechanism is to increase the amount of food eaten through changes in the hormones Leptin and Ghrelin. A study has shown that people who sleep less have lower levels of Leptin and higher levels of Ghrelin. A decrease from the 8 to 5 hour average night's sleep was related to a $15.5 \%$ leptin hormone reduction and a $14.9 \%$ Ghrelin hormone increase.

Leptin hormone regulates energy balance by adjusting hunger. Leptin functions are contrary to the hormone Ghrelin, a hormone produced by the digestive tract to create hunger. These hormones specifically work on particular receptors in the hypothalamic arcuate nucleus to regulate appetite. The change of Leptin and high Ghrelin hormone level will eventually lead to increased appetite. ${ }^{8}$

A study by Patel \& Hu (2008) showed that in an environment where food is already available, the lack of sleep duration can provide increased opportunities for eating, especially if most of the free time is spent in sedentary activities. ${ }^{19}$ Results from the study conducted by Capers PL (2015) also showed that sleep deprivation will leads to positive energy balance, in which the energy intake is increased by $300 \mathrm{kcal} / \mathrm{d}$ and if sleep deprivation persists over time, it will eventually cause weight gain. ${ }^{11}$

\section{Conclusion}

The study conclude that sleep duration was related with excess BMI in young adults. However, a further larger prospective study with more objective measurement is required to confirm the conclusion and its mechanism.

\section{Acknowledgments}

The author would like to extend his utmost gratitude to all students of Faculty of Medicine, Universitas Airlangga who were willing to be the respondents of this study.

\section{CONFLICT OF INTEREST}

The author stated there is no conflict of interest in this study.

\section{REFERENCES}

1. Ford ES, Cunningham TJ, Croft JB. Trends in SelfReported Sleep Duration among US Adults from 1985 to 2012. Sleep 2015; 38: 829-832.

2. Jean-Louis G, Williams NJ, Sarpong D, Pandey A, Youngstedt S, Zizi F, Ogedegbe G. Associations between Inadequate Sleep and Obesity in the US Adult Population: Analysis of The National Health Interview Survey (1977-2009). BMC Public Health 2014; 14: 1-10.

3. Ferrie JE, Shipley MJ, Cappuccio FP, Brunner E, Miller MA, Kumari M, Marmot MG. A Prospective Study of Change in Sleep Duration: Associations with Mortality in the Whitehall II Cohort. Sleep Durat Mortal 2007; 30: 1659-1666.
4. World Health Organization. Controlling The Global Obesity Epidemic 2017, https://www.who.int/nutrition/topics/obesity/en/ (2017).

5. Kementerian Kesehatan Republik Indonesia. Riset kesehatan dasar 2013. Jakarta: Kementerian Kesehatan RI, 2013.

6. St-Onge M. Sleep-Obesity Relation: Underlying Mechanisms and Consequences for Treatment. Obes Rev 2017; 18: 34-39.

7. Patel SR, Hayes AL, Blackwell T, Blackwell T, Evans DS, Ancoli-Israel S, Wing YK, Stone $\mathrm{KL}$, the Osteoporotic Fractures in Men (MrOS) and the Study of Osteoporotic Fractires (SOF) Research Groups. The Association between Sleep Patterns and Obesity in Older Adults. Int J Obes 2014; 38: 1159-1164.

8. Taheri S, Lin L, Austin D, Young T, Mignot E. Short Sleep Duration is Associated with Reduced Leptin, Elevated Ghrelin, and Increased Body Mass Index. PLoS Med 2004; 1: 210-217.

9. Bullen JJ, Bluher S, Kelesidis T, Mantzoros CS. Regulation of Adiponectin and its Receptors in Response to Development of Diet-Induced Obesity in Mice. Am J Physiol Endocrinol Metab 2007; 292: E1079-86.

10. Patel S, Malhotra A, Gottlieb D, White DP, Hu FB. Correlates of Long Sleep Duration. Natl Inst Heal 2005; 29: 881-889.

11. Capers P, Fobian A, Kaiser K, Borah R, Allison DB. A Systemic Review and Meta-Analysis of Randomized Controlled Trials of the Impact of Sleep Duration on Adiposity and Components of Energy Balance Patrice. Obes Rev 2015; 16: 771782.

12. Léger D, Du RE, Bayon V, Guignard R, Pâquereau J. Short sleep in young adults: Insomnia or sleep debt? Prevalence and clinical description of short sleep in a representative sample of 1004 young adults from France. Sleep Med 2011; 12: 454-462.

13. Gildner T, Liebert M, Kowal P, Chatterij S, Snodgrass JJ. Sleep Duration, Sleep Quality, and Obesity Risk among Older Adults from Six Middle-Income Countries: Findings from The Study on Global AGEing and Adult Health (SAGE). Am J Hum Biol 2014; 26: 803-812.

14. Sagala N, Sofyani S, Supriatmo. Association between Sleep Quality and Obesity in Adolescents. Paediatr Indones 2017; 57: 41

15. Marfuah D, Hadi H, Huriyati E. Durasi dan kualitas tidur hubungannya dengan obesitas pada anak sekolah dasar di Kota Yogyakarta dan Kabupaten Bantul. $J$ Gizi dan Diet Indones (Indonesian J Nutr Diet 2016; 1: 93.

16. Shi Z, Taylor AW, Gill TK, Tuckerman J, Adams R, Martin J. Short Sleep Duration and Obesity among Australian Children. BMC Public Health 2010; 10: 609

17. The National Sleep Foundation. National Sleep Foundation Recommends New Sleep Times. Natl Sleep Found 2015; 12-14.

18. Kanter R, Caballero B. Global Gender Disparities in Obesity: A Review. Adv Nutr 2012; 3: 491-498.

19. Patel S, HU F. Short Sleep Duration and Weight Gain: a Systematic Review. Natl Inst Heal 2008; 16: 643653. 
20. Dare S, Mackay DF, Pell JP. Relationship between Smoking and Obesity: A Cross-Sectional Study of 499,504 Middle-Aged Adults in the UK General Population. PLoS One 2015; 10: 1-12.
21. Zbikowski S, Magnusson B, Pockey J, Tindle HA,. A Review of Smoking Cessation Interventions for Smokers Aged 50 and Older. Maturitas 2012; 71: 131-141. 